\title{
Ausnahmsloses Werbeverbot ist nicht europakonform
}

\begin{abstract}
Die belgischen Werberegeln für Zahnärzte hat der Europäische Gerichtshof (EuGH) in seiner Entscheidung vom 4. Mai 2017 (C-339/15) überprüft. Vorschriften, die jegliche Werbung ausnahmslos verbieten, sehen die Richter als eine unzulässige Beschränkung der europäischen Dienstleistungsfreiheit an. Verboten werden darf aber weiterhin aggressive und irreführende Werbung, was insbesondere für die berufsrechtlichen Regelungen in Deutschland von Relevanz ist.
\end{abstract}

Der EuGH hält dabei auch stringente Werbeverbote unter dem Gesichtspunkt des Patientenschutzes und der Wahrung von Unabhängigkeit, Würde und Ehre des betreffenden reglementierten Berufs für zulässig.

Für den EuGH ist die maßgebliche europäische Richtlinie 2005/29 dahin auszulegen, dass sie nationalen Rechtsvorschriften nicht entgegensteht, die die öffentliche Gesundheit und die Würde des Zahnarztberufs schützen, indem sie zum einen jegliche Werbung für Leistungen der Mund- und Zahnversorgung allgemein und ausnahmslos verbieten und zum anderen bestimmte Anforderungen in Bezug auf die Schlichtheit von Zahnarztpraxisschildern stellen.

\section{Dienstleistungsfreiheit bei elektronischer Kommunikation}

Anders beurteilt der EuGH allerdings die Konstellation, wenn bei einem Werbeverbot jede Art kommerzieller Kommunikation auf elektronischem Weg, auch durch eine von einem Zahnarzt erstellte Website, verboten wird.

Werbung für Leistungen der Mund- und Zahnversorgung über eine Website, die von einem Angehörigen eines reglementierten Berufs erstellt wurde, sei eine kommerzielle Kommunikation, die im Sinne von Art. 8 der Richtlinie 2000/31 Bestandteil eines Dienstes der Informationsgesellschaft ist beziehungsweise einen solchen Dienst darstellt. Folglich seien die Mitgliedstaaten verpflichtet, sicherzustellen, dass solche kommerziellen Kommunikationen grundsätzlich erlaubt sind. Die vorstehende Regelung solle es Angehörigen eines reglementierten Berufs gerade ermöglichen, Dienste der Informationsgesellschaft $\mathrm{zu}$ nutzen, um ihre Tätigkeiten zu fördern.

Kommerzielle Kommunikation dürfte nur unter der Bedingung erlaubt werden, dass die berufsrechtlichen Regeln, insbesondere zur Wahrung von Unabhängigkeit, Würde und Ehre des betreffenden reglementierten Berufs, des Berufsgeheimnisses und eines lauteren Verhaltens sowohl gegenüber Kunden als auch gegenüber Berufskollegen, eingehalten werden.

Die berufsrechtlichen Regeln könnten jedoch nicht jegliche Form der Online-Werbung zur Förderung der Tätigkeit einer
Person, die einen reglementierten Beruf ausübt, allgemein und ausnahmslos verbieten, da der Bestimmung sonst ihre Wirksamkeit genommen würde.

\section{Berufsrecht kann Werbung stark einschränken}

Es sei zwar möglich, die Besonderheiten der Gesundheitsberufe bei der Ausarbeitung der berufsrechtlichen Regeln durch eine - gegebenenfalls starke - Eingrenzung der Formen und Ausgestaltungen der kommerziellen Online-Kommunikationen zu berücksichtigen, um unter anderem sicherzustellen, dass das Vertrauen der Patienten in diese Berufe nicht beeinträchtigt wird. Diese berufsrechtlichen Regeln könnten jedoch nicht zulässigerweise allgemein und ausnahmslos jede Form von Online-Werbung zur Förderung der Tätigkeit einer Person verbieten, die einen reglementierten Beruf ausübt.

In seiner Entscheidung stellt der EuGH weiter fest, dass ein intensives Betreiben von Werbung oder die Wahl von Werbeaussagen, die aggressiv oder sogar geeignet sind, die Patienten hinsichtlich der Versorgung irrezuführen, dem Schutz der Gesundheit schaden und der Würde des Zahnarztberufs abträglich sein könne, indem das Image des Zahnarztberufs beschädigt, das Verhältnis zwischen den Zahnärzten und ihren $\mathrm{Pa}$ tienten verändert und die Durchführung unangemessener oder unnötiger Behandlungen gefördert wird.

Allerdings gingen die Rechtsvorschriften in Belgien, nach denen jegliche Werbung für Leistungen der Mund- und Zahnversorgung allgemein und ausnahmslos verboten sind, aber über das hinaus, was nach der Judikatur des EuGH erforderlich sei. Der Gerichtshof habe zwar festgestellt, dass eine nationale Regelung möglich sei, die Werbung für medizinische Leistungen mit einem dem Berufsethos widersprechenden Inhalt verbietet. Allgemein und ausnahmslos jegliche Form der Werbung zu verbieten, sei aber nicht europakonform.

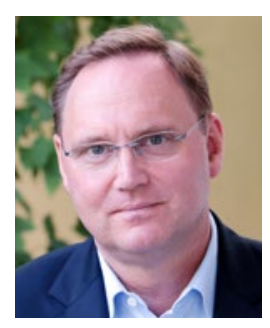

RA Michael Lennartz

www.lennmed.de 